\title{
Errata: Multimodality bronchoscopic imaging of tracheopathica osteochondroplastica
}

\section{Henri Colt}

Septimiu D. Murgu

University of California School of Medicine

Pulmonary and Critical Care Medicine

Department of Medicine

101 the City Drive South

Building 53, Room 119

Route 81 Orange, California 92868

E-mail: hcolt@uci.edu

\section{Yeh-Chan Ahn}

\section{Matt Brenner}

University of California, Irvine

Beckman Laser Institute

1002 Health Sciences Road

Irvine, California 92612

[DOI: $10.1117 / 1.3223334]$

This article [J. Biomed. Opt. 14, 034035 (2009)] was originally published online on 25 June 2009 with an error in the title and running head. The word "bronchoscopic" was misspelled as "bonchoscopic." All online versions of the article were corrected on 13 July 2009 and the article appears correctly in print. 